\title{
An Integrative Modeling and Experimental Study on the Ionic Resistance of Ion-Exchange Membranes
}

Bopeng Zhang ${ }^{a}$, Jin Gi Hong ${ }^{b}$, Shihua Xie ${ }^{a}$, Shuman Xia ${ }^{c}$, Yongsheng Chen ${ }^{a^{*}}$

${ }^{a}$ School of Civil and Environmental Engineering, Georgia Institute of Technology, Atlanta, Georgia 30332,United States

${ }^{\mathrm{b}}$ Department of Civil Engineering and Construction Engineering Management, California State University, Long Beach, CA, 90840, United States

${ }^{c}$ The George W. Woodruff School of Mechanical Engineering, Georgia Institute of Technology, Atlanta, Georgia 30332,United States

* Corresponding author.

E-mail: yongsheng.chen@ce.gatech.edu; Phone: (+1) 404-894-3089

Submitted to

Journal of Membrane Science

(C) 2016. This manuscript version is made available under the Elsevier user license http://www.elsevier.com/open-access/userlicense/1.0/ 


\section{Abstract}

2 In many applications, the ionic resistance of an ion-exchange membrane shows a strong

3 dependency on the external solution concentration and hydrodynamic environment. It is

4 critical to understand the insights of ion exchange membrane process if its ionic

5 resistance can be simulated accurately. In this paper, we have developed a new model by

6 taking into account both the membrane properties that affect the membrane bulk

7 resistance and hydrodynamic environment that affects the non-ohmic behavior of

8 membrane resistance. The new model not only explains external solution concentration

9 dependency, but also explicitly establishes a relationship between the measured

10 membrane resistance and current density. The modeling results on the direct current (DC)

11 and alternating current (AC) resistance of membranes are compared with experimental

12 data measured under different external solution concentrations and applied to current

13 densities. We demonstrate that the model accurately predicts the behaviors of sulfonated

14 polypoly (2,6-dimethyl-1,4-phenylene oxide) membranes and fumasep ${ }^{\circledR}$-FKS and FAS

15 membranes in all cases. The integrative modeling and experimental study provides

16 insights into the ion-exchange membrane synthesis as well as reverse and conventional

17 electrodialysis processes.

18

19 Keywords: Ionic resistance; ion-exchange membranes; diffusion boundary layer; reverse

20 electrodialysis. 


\section{1. Introduction}

23 Ion-exchange membranes are widely used in various electrochemical systems [1-6]. Key

24 membrane properties, such as electrical resistance and permselectivity, usually maintain

25 the functionality and determine the efficiency of these systems. The selectivity of ion-

26 exchange membranes enables the separation of cations and anions in a solution thereby

27 making electrodialysis and deionization processes possible. The efficiency of system

28 operation depends on the overall electrical resistance of the system which is significantly

29 determined by membrane resistance. For example, salinity gradient energy generated

30 through reverse electrodialysis (RED), has been a hot topic for researchers who see ion-

31 exchange membranes as the key component of RED conversion [7-9]. In this application,

32 Membrane resistance is critical in this application since the output power density is

33 directly affected by energy lost from electrical resistance.

34 The ionic resistance of an ion-exchange membrane is commonly determined by

35 experimental methods using direct current (DC) or by electrical impedance spectrometry

36 (EIS) using alternating current (AC) while the membrane is immersed in a $\mathrm{NaCl}$ or $\mathrm{KCl}$

37 solution [10-18]. Because concentration polarization occurs due to ionic current flow,

38 diffusion boundary layers (DBLs) evolve on both sides of the membrane and are

39 characterized by a change in the electrolyte concentration near the solution-membrane

40 interface. As a result, the measured membrane resistance varies significantly when the

41 measurement is taken under different operating conditions (i.e., different external

42 solution concentrations or applied current densities) [12, 19, 20]. Previous studies treated

43 this complexity as the overpotential and modeled using EIS, while the overall system

44 resistance was estimated using experimental values $[6,12,19,21]$. The boundary layer 
45 effects near the solution-membrane interface have also been investigated in several

46 reported studies [17, 22-25].

47 However, reliable information on the concentration-dependency of membrane resistance

48 is lacking, and the effect of electrical current density has not been explored in detail [22,

49 26]. For applications such as RED and electrodialysis, each membrane is not in contact

50 with electrolyte solution of same concentration on both sides and the electrical current in

51 the system may vary. Consequently, the commonly used value of membrane resistance

52 measured under these conditions does not represent the apparent resistance of a

53 membrane in these systems. An RED system model using this approach is not fully

54 applicable if the internal resistance is determined on the basis of the summation of the

55 separately measured resistances of the membrane and other components [12, 17, 27-30].

56 Furthermore, the electrochemical properties of membrane material and its relationship to

57 resistance is important to the synthesis of the membrane. The extent of improvement

58 attainable through optimization of membrane properties can be limited by the

59 environment of membrane application. The results of this limitation have led to a need

60 for further research on how the membrane properties can be better managed so as to

61 benefit from the environment. Therefore, this article aims to develop a novel membrane

62 resistance model that provides a comprehensive description of the apparent resistance of

63 cation-exchange membranes (CEMs) and anion-exchange membranes (AEMs). The

64 model is derived directly from the membrane's electrochemical properties under different

65 operating conditions. 


\section{Model Development}

67 According to the classical electrochemical analysis of a solution with diffusion limiting

68 transport, the solution-membrane interface concentration of salt varies with the density of

69 the electrical current flowing through the solution $[25,30]$. In a sodium chloride solution,

$70 \mathrm{Na}^{+}$and $\mathrm{Cl}^{-}$ions carry the electrical current fairly equally. However, in the membrane

71 phase, only counter-ions are the major carriers of current. The difference in the counter-

72 ion transport numbers in the solution and in the membrane phase causes a gradient of

73 concentration perpendicular to the membrane plane that is usually called "concentration

74 polarization" [3]. As a result, on one side of the membrane, the counter-ion (ions having 75 opposite charge compared to membrane bulk material) is approaching the membrane-

76 solution interface. Because of a faster transport of counter-ion across the membrane and

77 the migration of co-ion (ions with the same charge as membrane bulk material),

78 electroneutrality is maintained and generates a depletion of salt concentration. On the

79 other side accumulation of counter-ion due to a sudden decrease of transport

80 accompanied with migration of co-ion maintains the electroneutrality and generates an

81 accumulation of salt concentration. The concentration obeys a linear decrease while

82 approaching the membrane surface at a steady state when transport is stabilized.

\section{$83 \quad 2.1$ Non-ohmic Resistance in DBLs}

84 As shown in Figure 1, the salt concentration at the solution-membrane interface is a

85 function of the applied current density $(i)$ and limiting current density $\left(i_{\text {lim }}\right)$. Eq. 1a

86 describes the concentration variation on the depleting side of DBL and Eq. $1 \mathrm{~b}$ on the 87 accumulating side $[25,31]$. 
$88 \quad C_{1}^{b}(i)=C_{0}\left(1-\frac{i}{i_{\lim }}\right)$

89

$$
C_{2}^{b}(i)=C_{0}\left(1+\frac{i}{i_{\lim }}\right)
$$

90 where $C$ is the concentration of salt $(\mathrm{mol} / \mathrm{L})$, the subscripts 1 and 2 indicate the depleting

91 and accumulating sides, respectively, and $C_{0}$ is the concentration of the bulk solution.

92 The superscript $b$ indicates that the concentrations concerned at the solution-membrane

93 interface.

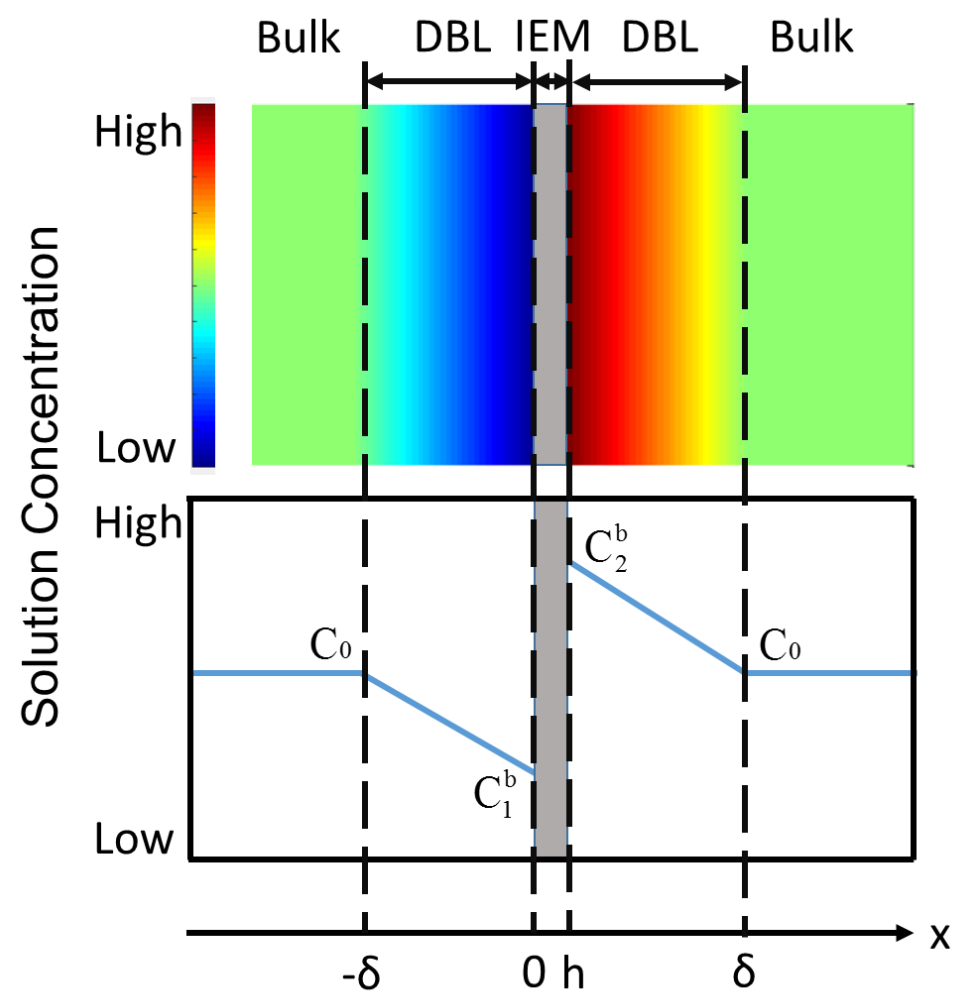

94

95 Figure 1. Diffusion boundary layer (DBL) near the surface of a cation-exchange 96 membrane and the salt concentration distribution in different layers at steady state. 97 Current direction is to the right. This illustrates the common situation in which the 98 membrane resistance is measured with the same bulk solution concentration on both sides 99 of the membrane using direct current. The left side shows a depleting side of DBL and 100 the right side shows an accumulating side of DBL. (The schematic is not drawn to scale.) 
102 At steady state, the concentration gradient in the DBL is assumed to be constant $[31,32]$.

103 From Figure 1, the concentration in the DBL as a function of distance $(x)$ to the interface

104 can be expressed as:

$105 \quad C_{1}(x)=C_{1}^{b}+\frac{C_{1}^{b}-C_{0}}{\delta} x$

$106 \quad C_{2}(x)=C_{2}^{b}-\frac{C_{2}^{b}-C_{0}}{\delta}(x-h)$

107 where $h$ is the thickness $(\mathrm{m})$ of the membrane and $\delta$ is the thickness $(\mathrm{m})$ of the DBLs as

108 shown in Figure 1. Because the flow rate and dimension of equipment are kept the same

109 for different situations studied in this work, the thickness of DBLs on both sides are

110 assumed to be the same as determined by flow rate [33-35]. Then, the resistances of the

111 electrolyte $\left(R_{L 1}\right.$ and $R_{L 2}$ in $\left.\Omega \cdot \mathrm{m}^{2}\right)$ from the DBLs on each side of the membrane are given

112 by the integral over the thickness of each DBL [25]:

$113 \quad R_{L 1}=\int_{-\delta}^{0} \frac{1}{\kappa_{1}} d x=\int_{-\delta}^{0} \frac{1}{\Lambda \cdot C_{1}(x)} d x=\frac{\delta}{\Lambda \cdot\left(C_{0}-C_{1}^{b}\right)} \ln \frac{C_{0}}{C_{1}^{b}}$

$114 R_{L 2}=\int_{h}^{h+\delta} \frac{1}{\kappa_{2}} d x=\int_{h}^{h+\delta} \frac{1}{\Lambda \cdot C_{2}(x)} d x=\frac{\delta}{\Lambda \cdot\left(C_{0}-C_{2}^{b}\right)} \ln \frac{C_{0}}{C_{2}^{b}}$

115 where $\kappa_{1}$ and $\kappa_{2}$ are the conductivities $(\mathrm{S} / \mathrm{m})$ of the DBLs, and $\Lambda$ is the molar conductivity

116 of the salt solution $\left(\mathrm{S} \cdot \mathrm{m}^{3} / \mathrm{mol}\right)$. The $x$-axis is the direction perpendicular to the membrane

117 surface. Combining Eqs. 3a and 3b, and substituting Eqs. 1a and 1b into Eq. 3, we obtain

$118 \quad R_{L}=\left(\frac{\delta}{r \cdot \Lambda} \ln \frac{1+r}{1-r}\right) \cdot \frac{1}{C_{0}}$

$119 \quad r=\frac{i}{i_{\lim }}$ 
120 The above equation represents a change in the electrolyte conductivity as a result of

121 concentration polarization. If the transport numbers of cations and anions are different in

122 the solution phase (e.g., $\mathrm{NaCl}$ solution), a diffusion potential exists, and are denoted as

$123 E_{d 1}$ and $E_{d 2}$ indicating depleting and accumulating sides, respectively. The resultant

124 resistances can be expressed as:

$125 \quad R_{d 1}=\frac{E_{d 1}}{i}=-\frac{R T}{i F} \Delta t \ln \frac{a_{0}}{a_{1}^{b}}$

$126 \quad R_{d 2}=\frac{E_{d 2}}{i}=-\frac{R T}{i F} \Delta t \ln \frac{a_{2}^{b}}{a_{0}}$

127 Here, $\Delta t$ is the difference of ion transport numbers in the solution phase. Adding Eqs. $6 \mathrm{a}$

128 and $6 \mathrm{~b}$ together and substituting Eqs. $1 \mathrm{a}$ and $1 \mathrm{~b}$ to replace the concentration term, we can

129 obtain Eq. 7.

$130 \quad R_{d}=\frac{R T}{i F} \Delta t \cdot \ln \frac{a_{2}^{b}}{a_{1}^{b}}=\frac{R T}{i F} \Delta t \cdot \ln \frac{\gamma_{2} C_{2}^{b}}{\gamma_{1} C_{1}^{b}}=\frac{R T}{i F} \Delta t\left(\ln \frac{1+r}{1-r}+\ln \frac{\gamma_{2}}{\gamma_{1}}\right)$

131 Here, $\gamma$ indicates the activity coefficient. The minus sign, which indicates that the

132 direction of the potential is opposite to that of the direct of current, is dropped for

133 resistance calculation. While the concentration on both sides are not the same, as in the

134 case of concentration polarization, a membrane potential $E_{m}^{D B L}$ is generated. The potential

135 is reflected as a resistance that can be expressed in Eq. 8 [36]. The minus sign is dropped

136 here as well as in resistance calculation.

$$
R_{m}^{D B L}=\frac{E_{m}^{D B L}}{i}=\frac{R T}{i F} \Delta \bar{t} \cdot \ln \frac{a_{2}^{b}}{a_{1}^{b}}=\frac{R T}{i F} \Delta \bar{t} \cdot \ln \frac{\gamma_{2} C_{2}^{b}}{\gamma_{1} C_{1}^{b}}=\frac{R T}{i F} \Delta \bar{t}\left(\ln \frac{1+r}{1-r}+\ln \frac{\gamma_{2}}{\gamma_{1}}\right)
$$

138 where $\Delta \bar{t}$ represents the difference of transport numbers of counter-ions and co-ions in 139 the membrane phase. 


\section{$141 \quad 2.2$ Resistance of Membrane Bulk Material}

142 Because only the solution phase in the membrane structure is conductive, the transport

143 properties considered here concern only the membrane-phase solution and salt ions inside

144 the solution. Also, the electrochemical properties of the membrane are treated as being

145 homogeneous.

146 Using the 1-D Nernst-Planck equation, we only deal with the case where the valence of

147 the ions is unity (because sodium chloride is the only salt used here). Also, we assume a

148 steady-state convection; thus, the DBL is stable near the membrane solution interface.

149 Finally, the diffusion and migration can be described using the Nernst-Einstein equation

150 (Eq. 9), for a species $k$ :

$151 \quad u_{k}=\frac{D_{k} F}{R T}$

$152 \quad J_{k}=-D_{k} \frac{d C_{k}}{d x}-u_{k} C_{k} \frac{d \varphi}{d x}=-D_{k} \frac{d C_{k}}{d x}-D_{k} \frac{C_{k} F}{R T} \frac{d \varphi}{d x}$

153 where $J_{k}$ is the flux of ions $\left(\mathrm{mol} /\left(\mathrm{m}^{2} \cdot \mathrm{s}\right)\right)$ in the solution, $D_{k}$ is the diffusivity of an ion

154 species $\left(\mathrm{m}^{2} / \mathrm{s}\right), \varphi$ is the external electrical potential applied to the system $(\mathrm{V}), u_{k}$ is the

155 mobility of ions $\left(\mathrm{m}^{2} /(\mathrm{V} \cdot \mathrm{s})\right), R$ is the gas constant, $F$ is the Faraday constant, and $T$ is the

156 temperature (K). Moreover, the diffusion term can be further defined such that the current

157 density is [30]:

$158 \quad i=F \sum_{k} J_{k}=-F^{2} \sum_{k} \frac{C_{k} D_{k}}{R T}\left(\frac{R T}{C_{k} F} \frac{d C_{k}}{d x}+\frac{d \varphi}{d x}\right)=-F^{2} \sum_{k} \frac{C_{k} D_{k}}{R T}\left[\frac{d}{d x}\left(\frac{R T}{F} \ln C_{k}\right)+\frac{d \varphi}{d x}\right]$ 
159 Both terms in the bracket have the dimension of potential gradient and thus can further be

160 expressed in a combined form (the electrochemical potential gradient if the pressure

161 components are neglected). Let the combined potential be $\Phi(\mathrm{V})$, then,

$162 i=-F^{2} \sum_{k} \frac{C_{k} D_{k}}{R T} \frac{d \Phi}{d x}$

163 However, Ohm's law states that the conductivity $\kappa(\mathrm{S} / \mathrm{m})$ is:

$164 i=\kappa \frac{d \Phi}{d x}$

165 Thus, by substituting Eq. 12 into Eq. 13, the conductivity of the membrane phase solution

166 is:

$167 \kappa=F^{2} \sum_{k} \frac{C_{k}^{m} D_{k}^{m}}{R T}$

168 The superscript $m$ indicates that the value is for the membrane phase. Note that the minus

169 sign only indicates the direction of the current in Eq. 12 and is neglected in Eq. 13.

170 Finally, if we assume the concentration is uniform within the membrane phase for both

171 counter- and co-ions, we can conclude that the ionic resistance of the solution in the

172 membrane phase $\left(R_{m}\right)$ is:

$173 \quad R_{m}=\int_{0}^{h} \frac{d x}{\kappa^{m}}=\int_{0}^{h} \frac{R T}{F^{2} \cdot\left(D_{c t}^{m} C_{c t}^{m}+D_{c o}^{m} C_{c o}^{m}\right)} d x=\frac{h R T}{F^{2} \cdot\left(D_{c t}^{m} C_{c t}^{m}+D_{c o}^{m} C_{c o}^{m}\right)}$

174 The subscripts $c t$ and $c o$ indicate counter-ion and co-ion, respectively. The counter- and

175 co-ion concentrations in the membrane phase can be derived from the Donnan 176 equilibrium [37]:

$177 \quad C_{c t}^{m}=\frac{C_{f i x}}{2}+\sqrt{\left(\frac{C_{f i x}}{2}\right)^{2}+\left(C_{i}^{\delta}\right)^{2}}$ 
$178 \quad C_{c o}^{m}=-\frac{C_{f i x}}{2}+\sqrt{\left(\frac{C_{f i x}}{2}\right)^{2}+\left(C_{i}^{\delta}\right)^{2}}$

179 where $C_{f i x}$ is the fixed charge density (FCD) (eq./L) in the ion-exchange membrane. It is

180 calculated as the ratio of ion exchange capacity (IEC) to swelling degree (SD):

$181 \quad C_{f i x}=\frac{I E C}{S D}$

182 The co-ion concentration can be assumed to be negligible in the membrane due to

183 Donnan exclusion. In the concentration range concerned in this study, co-ion

184 concentration is two orders of magnitude lower than counter-ion concentration in the

185 membrane [36]. Furthermore, from Eq. 10a, if the concentration at the solution-

186 membrane interface $C^{b}$ is relatively small compared to $C_{f i x}$, the counter-ion concentration

187 is very close to $C_{f i x}$. Then Eq. 9 becomes:

$188 \quad R_{m}=\frac{h R T}{F^{2} \cdot\left(D_{c t}^{m} C_{c t}^{m}+D_{c o}^{m} C_{c o}^{m}\right)} \cong \frac{h R T}{F^{2} D_{c t}^{m} C_{f i x}}$

189 The assumption here is well justified with a typical membrane used in this study. For

190 example, the sPPO membrane has a fixed charge density of $5.15 \mathrm{~mol} / \mathrm{L}$ using Eq. 17,

191 which results in a counter-ion concentration of $5.20 \mathrm{~mol} / \mathrm{L}$ in the $\mathrm{NaCl}$ solution of 0.5

$192 \mathrm{~mol} / \mathrm{L}$ as indicated in Eq. 16a. This result is in agreement with the model used in the

193 electrodialysis field $[18,23]$. Furthermore, because the counter-ion considered can be

194 different in CEMs and AEMs, the derivation is valid to either type of IEM. For

195 simplicity, the membrane-property-related parameters $D_{c t}^{m}$ and $C_{f i x}$ are denoted as a single

196 parameter $M$.

197

$198 \quad$ 2.3 The Measurement of Resistance Under DC Conditions 
199 The common measurement of membrane resistance using the DC method is severely

200 affected by the DBL; in fact, the resulting resistance is partly caused by the DBL even

201 under vigorous stirring [19]. If the resistance is measured with the same concentration of

202 solution on both sides of the membrane, the reported result $\left(R_{0}\right)$ is the difference between

203 the experimental $\left(R_{E}\right)$ and blank $\left(R_{B L}\right)$ resistances compensated by the solution resistance

204 that has the same resistance of solution with thickness $h$ [38]:

$205 \quad R_{0}=R_{E}-R_{B L}+\frac{h}{\Lambda \cdot C_{0}}$

206 We neglect all resistances other than the resistance raised due to the formation of DBL

207 because subtraction of the blank removes such resistances from the final result. During

208 DC measurement of membrane resistance with the same bulk solution concentration on

209 both sides of the membrane, the combination of the four resistances from Eqs. 4, 7, 8 and

21018 gives the total resistance of the membrane as it adds up the change of resistance in

211 DBL, the diffusion generated resistance, and the membrane-potential-related resistance:

$212 \quad R_{E}=R_{L}+R_{d}+R_{m}^{D B L}+R_{m}$

213 The blank resistance to be subtracted is calculated as the resistance of the solution that

214 replaces the two DBLs and the membrane bulk in thickness:

$215 \quad R_{B L}=\frac{2 \delta+h}{\Lambda \cdot C_{0}}$

216 Thus, Eq. 19 becomes:

$217 \quad R_{0}=a \cdot \frac{1}{C_{0}}+b$

$218 \quad a=\frac{\delta}{r \cdot \Lambda} \ln \frac{1+r}{1-r}-\frac{2 \delta}{\Lambda}$ 
$219 \quad b=\frac{h R T}{F^{2} M}+\frac{R T(\Delta t+\Delta \bar{t})}{r i_{\lim } F} \cdot\left(\ln \frac{1+r}{1-r}+\ln \frac{\gamma_{2}}{\gamma_{1}}\right)$

220 As a result, the resistance measured by the DC method is dependent on the external 221 solution concentration $C_{0}$. The linear relationship between the measured resistances and 222 the reciprocal of the bulk solution concentration is expected. Furthermore, it can be 223 proved using L'Hôpital's rule that the " $a$ " term in front of the reciprocal of concentration 224 approaches to two when $r$ approaches zero (i.e., no electrical current flow). 


\section{Materials and Methods}

\section{$226 \quad 3.1$ Synthesis of sPPO membrane}

227 Poly (2,6-dimethyl-1,4-phenylene oxide) (PPO), analytical standard grade, was purchased 228 from Sigma Aldrich. The PPO sulfonation was carried out according to the procedure 229 described in the literature [8, 39]. Chloroform (Sigma Aldrich, anhydrous, $99 \%$ ) and

230 methanol (Sigma Aldrich, anhydrous, $99.8 \%$ ) were used as solvents, and chlorosulfonic 231 acid (VWR, 99\%) was used as the sulfonating agent.

\section{$233 \quad 3.2$ Membrane resistance measurement using DC}

234 Membrane samples were placed between two PMMA (poly(metyl 2-methylpropenoate)) 235 cells each with a volume of $460 \mathrm{ml}(7.6 \mathrm{~cm} \times 7.6 \mathrm{~cm} \times 8 \mathrm{~cm})$ (Figure 2). Sodium

236 chloride solution was supplied at a flow rate of $60 \mathrm{ml} / \mathrm{min}$ by a Masterflex ${ }^{\circledR}$ peristaltic 237 pump (Cole-Parmer, USA). The membrane had an effective area of $7.9 \mathrm{~cm}^{2}$. Before the 238 measurement, membranes were equilibrated with the corresponding solution $(0.01$ $239 \mathrm{~mol} / \mathrm{L}-0.5 \mathrm{~mol} / \mathrm{L} \mathrm{NaCl}$ ) for at least $24 \mathrm{~h}$. On each end of the cell, two titanium mesh 240 electrodes coated with iridium were used as working and counter electrodes; two 241 silver/silver chloride electrodes were used as reference electrode and placed in Luggin 242 capillaries at fixed positions with a tip-to-tip distance of $3 \mathrm{~mm}$ on two sides of the 243 membrane. Direct electrical current was applied to the system in a galvanostatic mode

244 with six current steps using an Ivium potentiostat (Vortex ${ }^{\circledR}$, Ivium Technologies, the 245 Netherlands). Each step was maintained for at least 30 seconds to reach a stable reading.

246 The measured current-voltage curve was used to obtain membrane resistance based on 247 the slope of the curve [13]. Because the limiting current density is a function of solution 
248 concentration, we used different current steps for different solution concentrations. For

$2490.01 \mathrm{~mol} / \mathrm{L}$ solution, the maximum current density of $3.79 \mathrm{~A} / \mathrm{m}^{2}$ was achieved after six

250 equal steps; for $0.017 \mathrm{~mol} / \mathrm{L}$ solution, the maximum current density was $7.59 \mathrm{~A} / \mathrm{m}^{2}$ in six

251 steps; for $0.05 \mathrm{~mol} / \mathrm{L}$ and $0.1 \mathrm{~mol} / \mathrm{L}$ solutions, the maximum current density was 26.5

$252 \mathrm{~A} / \mathrm{m}^{2}$ in six steps; and for $0.5 \mathrm{~mol} / \mathrm{L}$ solution, the maximum current density was 75.8

$253 \mathrm{~A} / \mathrm{m}^{2}$ in six steps. The current density used was kept far below the limiting current

254 density so that the current density effect was not obvious during the measurement except

255 for the cases of $0.01 \mathrm{~mol} / \mathrm{L}$ and $0.017 \mathrm{~mol} / \mathrm{L}$ solutions. In these two situations, the current

256 density ratio $r$ reached 0.55 . Three membranes of the same kind were measured as

257 replicates in all of the following measurements.

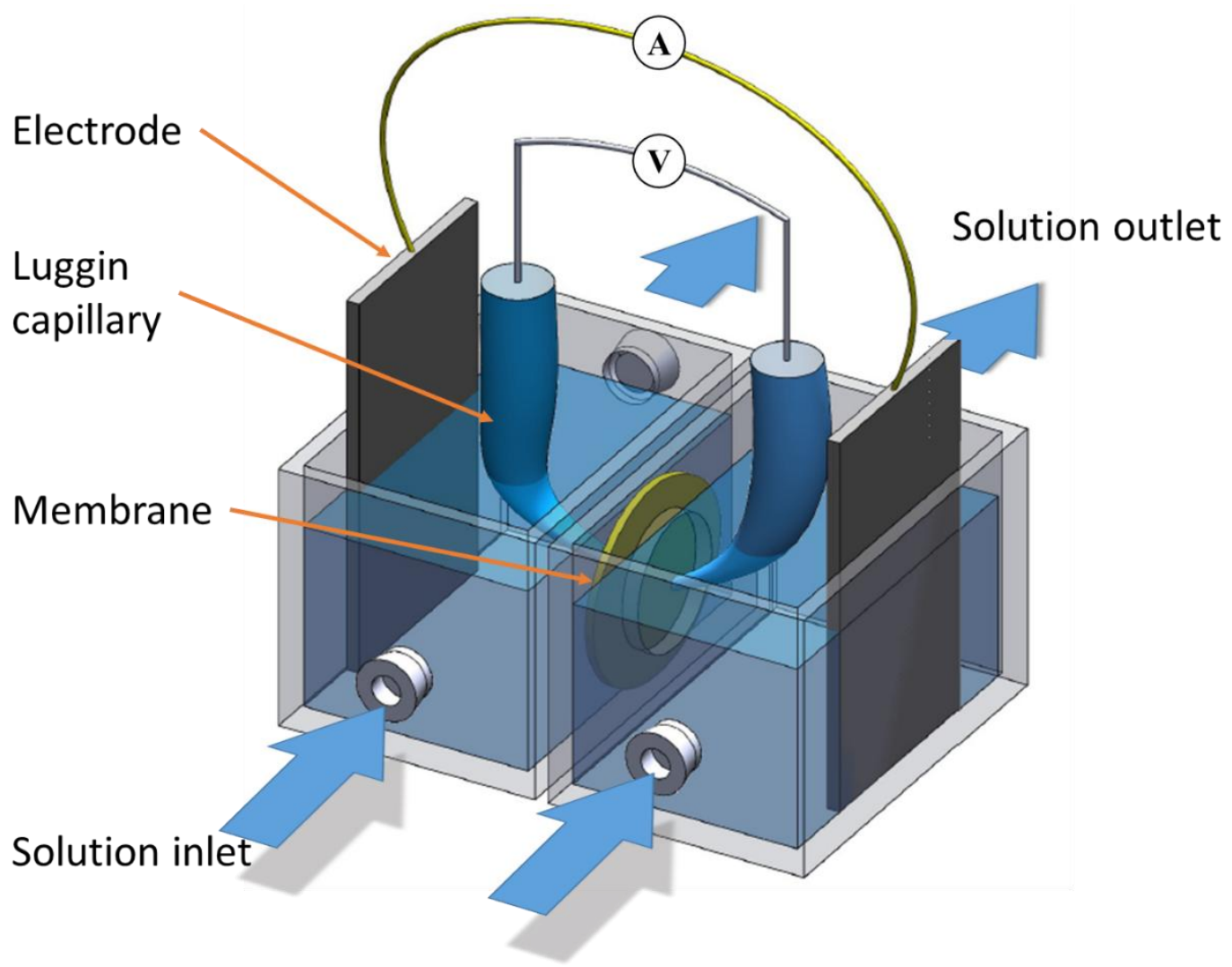

259 Figure 2. Experimental setup for DC and AC measurements. Titanium electrodes coated 260 with Iridium are pointed as 'Electrode'; $\mathrm{Ag} / \mathrm{AgCl}$ electrodes are placed in the 'Luggin 261 capillary'. 


\section{3.3 Membrane resistance measured by varying current density using DC}

264 To study the effect of applied current density on the resistance measurement, a method

265 has been developed to measure the resistance at a certain applied current density instead

266 of using the slope of I-V curve at different current densities. A similar method has been

267 reported in the literature [40]. The resistance is derived from the potential drop after a

268 single current jump. Sufficient time was allowed to reach a steady voltage state to reach

269 the steady-state (Figure 3). Multiple steps were applied to obtain resistance under

270 different current density ratios. In this approach, the resistance at a constant current

271 density ratio can be obtained.

272
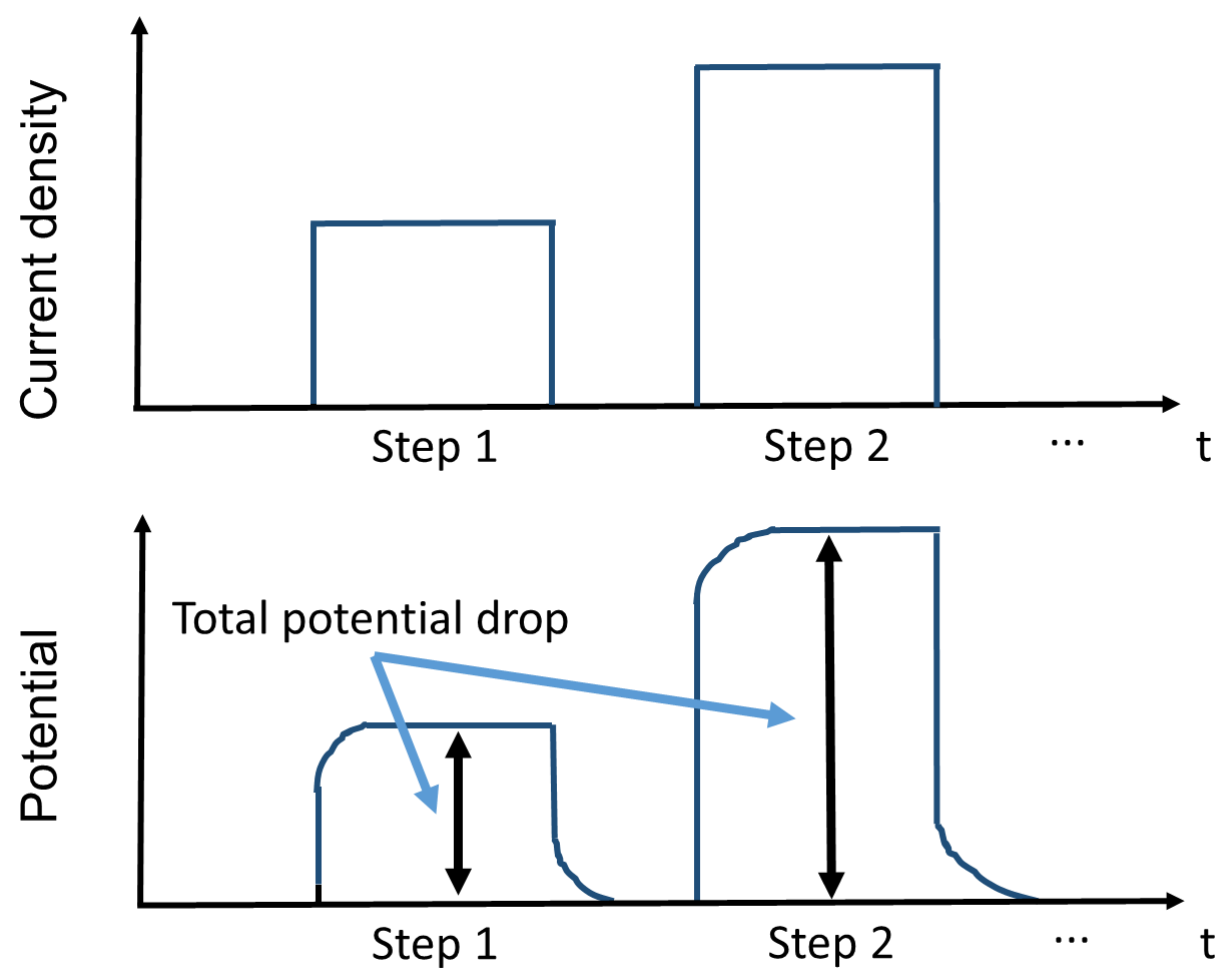

274 Figure 3. Schematic representation of method used to study the effect of current density. 275 Potentiostat controls the time and height of each current density step, and the total 
potential drop is measured until the steady state is reached. Used current density values

277 depend on the limiting current density of each membrane to obtain different current 278 density ratios $r$.

\subsection{Membrane resistance measurement using AC}

281 With the same setup, alternating current (AC) was applied to the system. Electrical

282 impedance spectroscopy was used to analyze results based on the model. Applied

283 frequency was set to $1000 \mathrm{~Hz}$ with five different current amplitudes from $1.8 \mathrm{~A} / \mathrm{m}^{2}$ to

$28435.5 \mathrm{~A} / \mathrm{m}^{2}$ with a step of $7 \mathrm{~A} / \mathrm{m}^{2}$. When the AC frequency was in this range, the

285 membrane bulk resistance along with solution resistance was measured [12, 15, 21]. A

286 following experiment without membrane was performed as a blank run. The pure

287 membrane resistance was calculated as the difference between the impedances obtained

288 in these two experiments.

\section{$289 \quad 3.5$ Modeling methodology}

290 The constants used in the model are listed in Table 1 . The molar conductivity of $\mathrm{NaCl}$ is 291 assumed to be constant in the concentration range discussed in this paper. The activity 292 coefficients were calculated based on the Debye-Hückel equation and the Davies 293 equation within their ranges of applicability, respectively. Simulation and graph

294 generation were conducted using MATLAB ${ }^{\circledR}$ R2013a (MathWorks, Natick, MA, USA)

295 and Microsoft Excel ${ }^{\circledR}$. The area resistance is calculated based on Eq. 19. The $\mathrm{NaCl}$

296 concentration range is between $0.010 \mathrm{~mol} / \mathrm{L}$ and $0.500 \mathrm{~mol} / \mathrm{L}$ to fall within the conditions

297 practically encountered during RED power generation. The temperature used in the 298 calculation is assumed to be $298 \pm 1 \mathrm{~K}\left(25 \pm 1{ }^{\circ} \mathrm{C}\right)$. Membrane properties (except 299 resistance) were taken as reported for frequently used IEMs in RED studies: CMX and 
300 AMX membranes were reported in the study by Dlugolecki et al. (2010) [14], and FKS

301 cation and FAS anion (FuMA-Tech, Bietigheim-Bissingen, Germany) membrane

302 properties along with SELEMION ${ }^{\mathrm{TM}}$ (AGC Engineering, Japan) according to

303 manufacturer's specifications [41]. These properties are listed in Table 2. 
304 Table 1. Nomenclature in the model simulation

\begin{tabular}{|c|c|c|}
\hline Parameter & Description & Value/Notes \\
\hline $\boldsymbol{F}$ & Faraday constant $(\mathrm{s} \cdot \mathrm{A} / \mathrm{mol})$ & 96485 \\
\hline $\boldsymbol{R}$ & Gas constant $(\mathrm{J} \cdot \mathrm{mol} / \mathrm{K})$ & 8.314 \\
\hline$T$ & Temperature $(\mathrm{K})$ & 298 \\
\hline$\Lambda$ & $\begin{array}{l}\text { Molar Conductivity of } \mathrm{NaCl} \text { Solution }(298 \mathrm{~K}) \\
\left(\mathrm{S} \cdot \mathrm{m}^{2} / \mathrm{mol}\right)\end{array}$ & $0.01265^{*}$ \\
\hline$\Delta t$ & $\begin{array}{l}\text { Difference of transport numbers of sodium } \\
\text { ion and chloride ion in water solution }\end{array}$ & -0.22 for CEM and 0.22 for AEM \\
\hline$\Delta \bar{t}$ & $\begin{array}{l}\text { Difference of transport numbers of sodium } \\
\text { ion and chloride ion in membrane phase }\end{array}$ & $\begin{array}{l}\text { Estimated from permselectivity [35, } \\
36]^{* *}\end{array}$ \\
\hline$\delta$ & Thickness of DBL (m) & $\begin{array}{l}\text { 1.0E-3 (fit value from FKS membrane, } \\
\text { used for other membranes) }\end{array}$ \\
\hline $\boldsymbol{h}$ & Thickness of membrane $(\mathrm{m})$ & - \\
\hline$D_{c t}^{m}$ & $\begin{array}{l}\text { Diffusivity of counter ion in membrane phase } \\
\left(\mathrm{m}^{2} / \mathrm{s}\right)\end{array}$ & - \\
\hline$C_{f i x}$ & Fixed charge density of membrane (eq./L) & - \\
\hline$a_{1}^{b}, a_{2}^{b}, a_{0}$ & $\begin{array}{l}\text { Activities of sodium chloride on both sides of } \\
\text { membrane and bulk solution }\end{array}$ & $\begin{array}{l}\text { Debye-Hückel model or Davies model } \\
\text { within their ranges of applicability }\end{array}$ \\
\hline$M$ & Membrane property parameter $\left(\mathrm{m}^{2} \cdot \mathrm{eq} . /(\mathrm{L} \cdot \mathrm{s})\right)$ & The product of $\boldsymbol{D}_{c t}^{\boldsymbol{m}}$ and $\boldsymbol{C}_{f i x}$ \\
\hline$i$ & Applied current density $\left(\mathrm{A} / \mathrm{m}^{2}\right)$ & - \\
\hline$i_{\text {lim }}$ & Limiting current density $\left(\mathrm{A} / \mathrm{m}^{2}\right)$ & $\begin{array}{l}\text { Measured at } 70.57 \text { (FKS), } 102.9 \text { (FAS), } \\
\text { and } 68.5 \text { (sPPO) in } 0.1 \mathrm{~mol} / \mathrm{L} \mathrm{NaCl} \\
\text { solution; assuming changing linearly } \\
\text { with respect to solution concentration } \\
\text { [36]. }\end{array}$ \\
\hline $\boldsymbol{r}$ & $\begin{array}{l}\text { Ratio of applied current density to limiting } \\
\text { current density }\end{array}$ & Within the range of 0 to 1 \\
\hline$C_{o}$ & Bulk solution concentration $(\mathrm{mol} / \mathrm{L})$ & - \\
\hline$\gamma$ & Activity coefficient & - \\
\hline $\boldsymbol{R}_{L}$ & $\begin{array}{l}\text { Resistance due to the change of electrolyte } \\
\text { concentration in diffusion boundary layer } \\
\left(\Omega \cdot \mathrm{m}^{2}\right)\end{array}$ & - \\
\hline $\boldsymbol{R}_{d}$ & $\begin{array}{l}\text { Resistance due to diffusion potential formed } \\
\text { in diffusion boundary layer }\left(\Omega \cdot \mathrm{m}^{2}\right)\end{array}$ & - \\
\hline $\boldsymbol{R}_{m}^{D B L}$ & $\begin{array}{l}\text { Resistance due to membrane potential formed } \\
\text { across membrane }\left(\Omega \cdot \mathrm{m}^{2}\right)\end{array}$ & - \\
\hline $\boldsymbol{R}_{\boldsymbol{0}}$ & Measure membrane resistance $\left(\Omega \cdot \mathrm{m}^{2}\right)$ & - \\
\hline $\boldsymbol{R}_{m}$ & $\begin{array}{l}\text { Membrane bulk resistance; assumed to be the } \\
\text { AC measurement result }\left(\Omega \cdot \mathrm{m}^{2}\right)\end{array}$ & - \\
\hline $\boldsymbol{R}_{E}$ & $\begin{array}{l}\text { Experimental resistance result (before } \\
\text { subtracting control run })\left(\Omega \cdot \mathrm{m}^{2}\right)\end{array}$ & - \\
\hline $\boldsymbol{R}_{B L}$ & Control run of resistance measurement $\left(\Omega \cdot \mathrm{m}^{2}\right)$ & - \\
\hline
\end{tabular}


$306 * *$ An approximate relationship has been used here $P \approx \frac{\bar{t}-t}{1-t}$, where, $\mathrm{P}$ is the 307 permselectivity of membrane, $t$ is the transport number of counter-ion in water phase and $308 \mathrm{t}^{-}$is the transport number of counter-ion in membrane phase $[35,36]$. 
309 Table 2. Properties of Related Ion Exchange Membranes

\begin{tabular}{llllll}
\hline & $\begin{array}{l}\text { IEC (meq/g dry } \\
\text { membrane) }\end{array}$ & $\begin{array}{l}\text { Permselectivity } \\
(\boldsymbol{\%})\end{array}$ & SD $(\boldsymbol{\%})$ & $\begin{array}{l}\text { Thickness } \\
(\boldsymbol{\mu m})\end{array}$ & References \\
\hline FKS & 1.47 & 98.3 & $33-41$ & $20-63$ & \\
FAS & $>1$ & 94.6 & $22-25$ & $20-54$ & \\
CMX & 1.64 & 92.5 & 21.5 & 181 & {$[14]$} \\
AMX & 1.30 & 91.0 & 16.4 & 138 & {$[14]$} \\
SPPO & 1.90 & 89.9 & 36.9 & $16-94$ & \\
\hline
\end{tabular}

310 


\section{4. Results and Discussion}

\section{4.1 Membrane resistance measured using AC}

313 FKS, FAS, and sPPO membranes of different thicknesses were measured using the AC

314 method. A linear relationship of area resistance to thickness is clearly illustrated in Figure

315 4. From Eq. 22, only the bulk resistance (term in value b) dominates when an alternating

316 electrical field with high frequency $(1000 \mathrm{~Hz}$ in this case) exists, because the polarization

317 effect is not evident when there is no net migration of ions in any direction. Therefore,

318 the membrane property parameter $M$ (combined indicator of fixed charge density and 319 interaction of counter-ions with membrane bulk material) is the only property that affects

320 the membrane resistance. For a certain type of membranes (e.g., sPPO membrane made

321 from the same batch of source material), $M$ remains constant regardless of the thickness

322 of the membrane. Consequently, the membrane resistance measured using the AC

323 method should exhibit a linear relationship against the thickness of the membrane. The

324 same assumption can be applied to commercial FKS and FAS membranes to evidence the

325 observed phenomena. In Figure 4, the interceptions on the y axis are all relatively small

326 (i.e., 0.09 for FKS, 0.07 for FAS, and 0.04 for sPPO). When the thickness of the

327 membrane approaches zero, the bulk resistance is also approaching zero (Eq. 18). The

328 slopes of these lines are different, indicating different membrane property parameters $M$. 


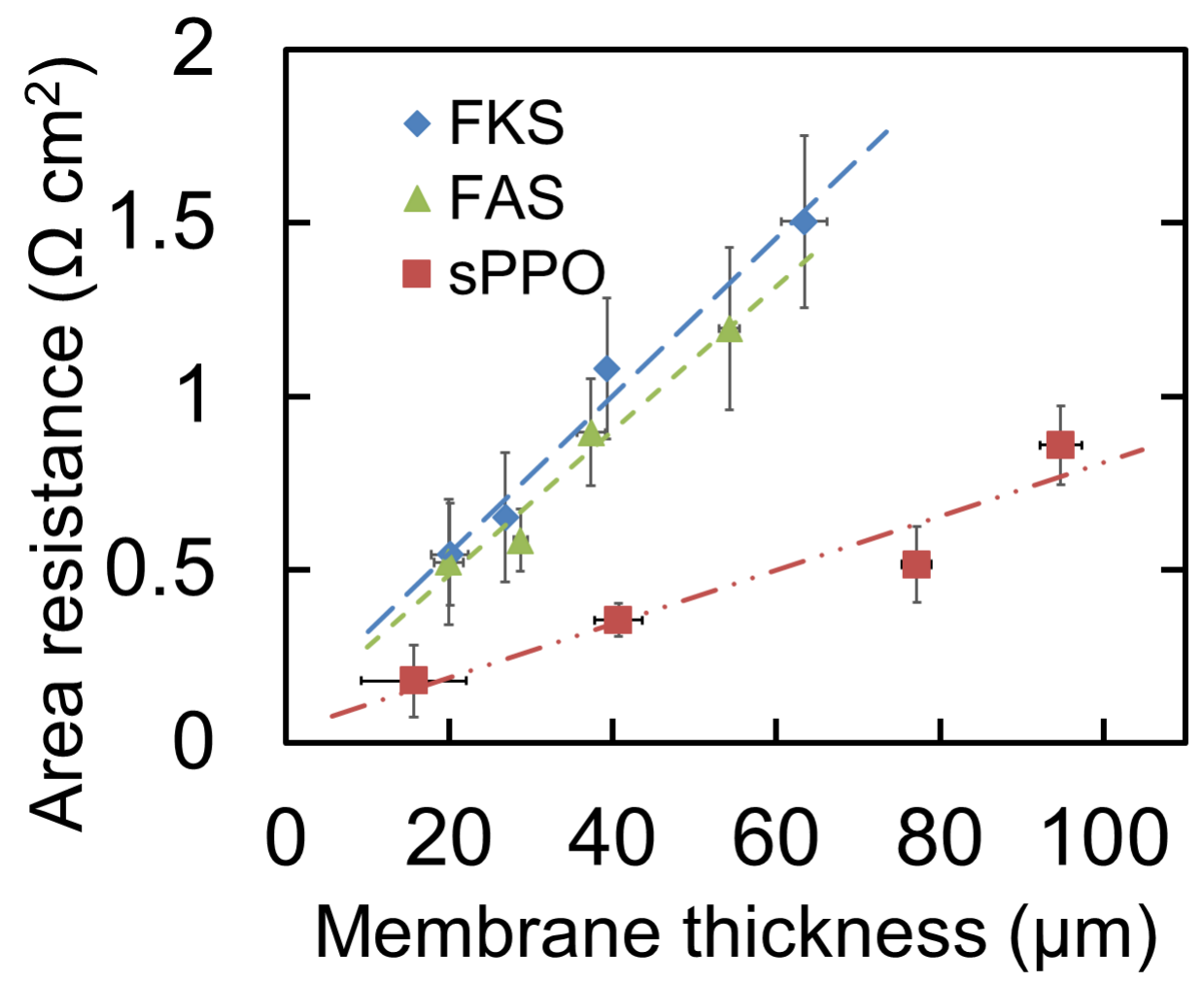

330 Figure 4. Membrane resistance measured using AC against membrane thickness. For 331 each kind of membrane, four different thicknesses were tested. Error bars show the 95\% 332 confidence interval of replicates during resistance and thickness measurements.

334 This linear relationship has been implied in the literature, but not specifically proved

335 because different membrane properties were compared [2]. Assuming that the membrane

336 property parameter $(M)$ is constant with a given membrane material, thinner membranes

337 should be advantageous as long as mechanical strength permits. However, as will be

338 discussed later, resistance measured using AC without significant boundary layer effect

339 presents the membrane bulk resistance and is, therefore, not a proper indicator of

340 membrane resistance in a system with DC current flow. By using this AC resistance to

341 represent membrane bulk resistance, term $b$ in Eqs. 22 can be further evaluated in DC

342 studies. 


\section{$344 \quad 4.2$ External concentration effect}

345 Membrane resistance was measured when the membrane was in contact with $\mathrm{NaCl}$

346 solution of different concentrations. The resistance obtained from AC studies was used as

347 bulk resistance $\frac{h R T}{F^{2} M}$ (as in term $b$ of Eq. 22) for each membrane. An optimized

348 hydrodynamic parameter (DBL thickness $\delta$ ) and current density ratio $\mathrm{r}$ were obtained

349 from fitting FKS membrane measurement results as $1.0 \mathrm{~mm}$ and 0.54 , respectively.

350 Results were not significantly different if FAS or sPPO data was used as the fitting data

351 (Supporting Information). The current density ratio is relative to the limiting current

352 density of FKS here. The current density ratio for different membrane varied with respect

353 to different limiting current densities (Table 1). Therefore, even the current applied

354 during the measurement was kept the same for different membrane, the resulting $r$ values

355 were different for different membranes. The same $\delta$ was used in all cases. As shown in

356 Figure 5, simulation results using the model correlate well with experimental data for the

357 FKS membrane, and the prediction matches well for FAS and sPPO data. The 358 coefficients of variance $\left(\mathrm{R}^{2}\right)$ are $0.951,0.938$, and 0.998 for FKS, FAS, and sPPO 359 membranes, respectively.

360 The assumption of the same DBL thickness for different membranes is appropriate

361 because both the solution flow rate and the distance between the two Luggin capillaries

362 were fixed in this study. Therefore, only the local flow pattern near the membrane surface

363 would affect the hydrodynamic environment $[34,43]$. Since the same testing cell was

364 used in all experiments (Figure 2), local variations should not be a significant concern.

365 The current density ratio $r$ used in the simulation and prediction was well justified for

366 low concentration situations $(0.01 \mathrm{~mol} / \mathrm{L}$ and $0.017 \mathrm{~mol} / \mathrm{L})$ as the current density used 
367 during the measurement could reach over half of the limiting current density. According

368 to Eq. 22, when the bulk solution concentration $\left(C_{0}\right)$ increases, the effect of current

369 density diminishes rapidly. In fact, the current density ratio $r$ varying under 0.55 did not

370 result in a significant difference of predicted resistance.

371

372
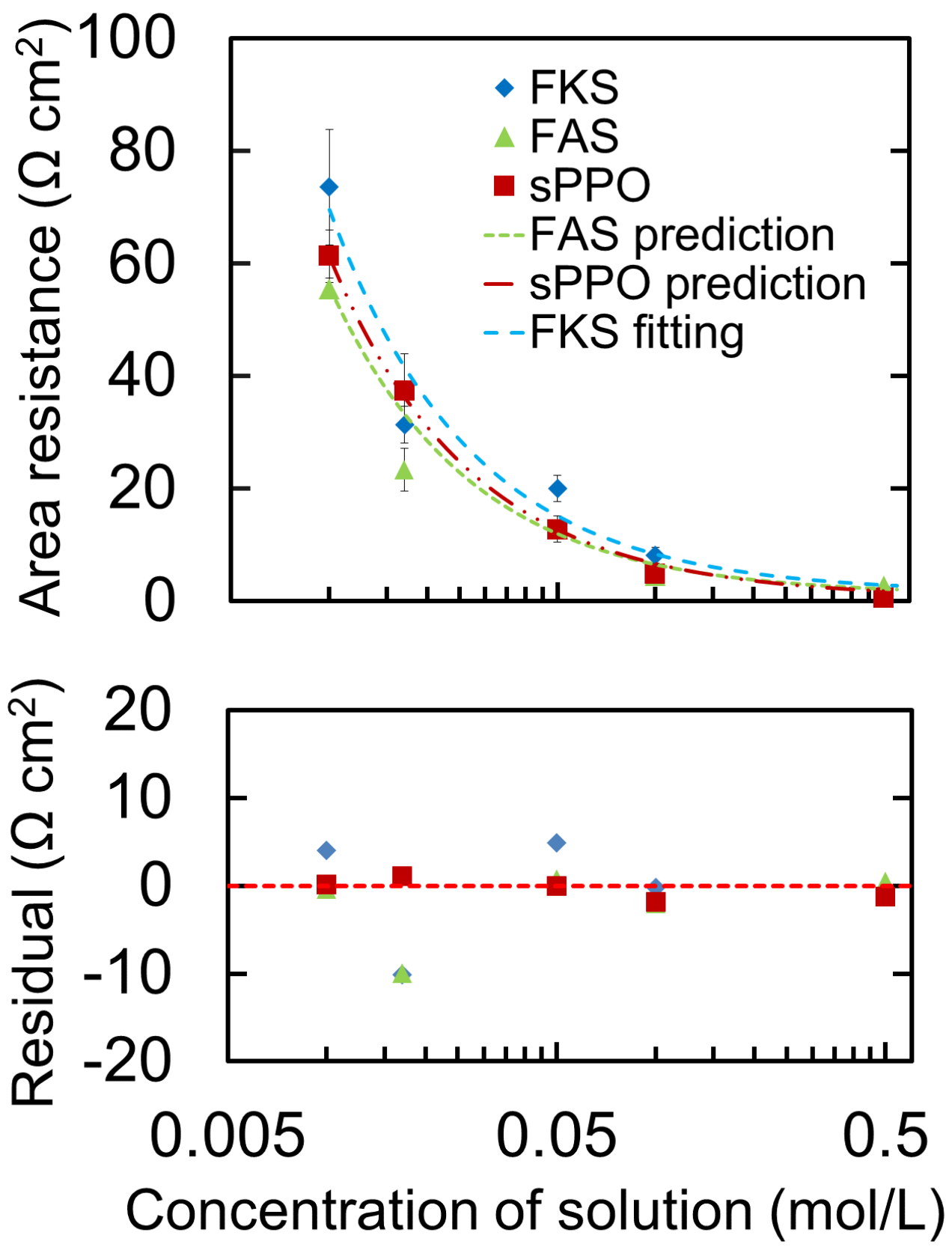
374 Figure 5. Concentration dependency of the membrane resistance is measured using DC 375 on FKS, FAS, and sPPO membranes. Simulation curve and experimental data are 376 compared and residues are presented.

To further validate the model, the simulation of resistances was fit to data reported in

380 Dlugolecki et al. (2010) for the commercially available CMX and AMX equilibrated in

381 different concentrations of $\mathrm{NaCl}$ solution [14]. The simulation curves matched well with

382 the measured resistances at various $\mathrm{NaCl}$ concentrations as seen in Figure 6. Note,

383 however, that a different value of $r=0.36\left(i / i_{\mathrm{lim}}\right)(\mathrm{Eq} .19)$ was used for best fit. The

384 difference in applied current density $(i)$ is reasonable since the measuring current density

385 does not exceed the limiting current density $(r<1)[14,19]$. The coefficients of variance

$386\left(\mathrm{R}^{2}\right)$ are 0.993 and 0.985 for CMX and AMX membrane fittings, respectively.

387 The increase of measured resistance along with the decrease of external solution 388 concentration has also been shown in other studies. For example, in the model developed

389 by Kim et al., (2013) [44], the membrane resistance has a linear relationship with the

390 reciprocal of external solution concentration. Their model was not able to explain the

391 situation when the membrane resistance plateaus at a certain level under sufficiently high

392 salt concentration instead of approaching zero. On the other hand, the model presented in

393 this work treats the term $a$ in Eq. 22 containing $1 / C_{0}$ as the term affected by external

394 concentration, which decreases rapidly as the bulk concentration increases. However, the

395 last term in Eq. 22, $\frac{h R T}{F^{2} M}$ (membrane bulk resistance) stays almost the same, which

396 explains the plateaus. Galama et al. (2014) also fit the resistance trend using a similar

397 form as seen in Eq. 22, but no physical meanings associated with the fitting parameters 398 were proved [21]. 
399 The strength of the presented model lies on the prediction of apparent resistance of 400 membrane when the current density varies. Obviously, the DBL thickness as an indicator 401 of hydrodynamic environment and membrane property $M$ and limiting current density in 402 a given concentration have to be given as inputs. Generally, $M$ may change according to 403 external concentration. However, because of the Donnan equilibrium, the assumption that 404 the counter-ion concentration in the membrane phase is relatively stable over a wide 405 concentration range is valid, especially when the concentration concerned is significantly 406 lower than the fixed charge density as shown in Eq. 16a [37].

407 

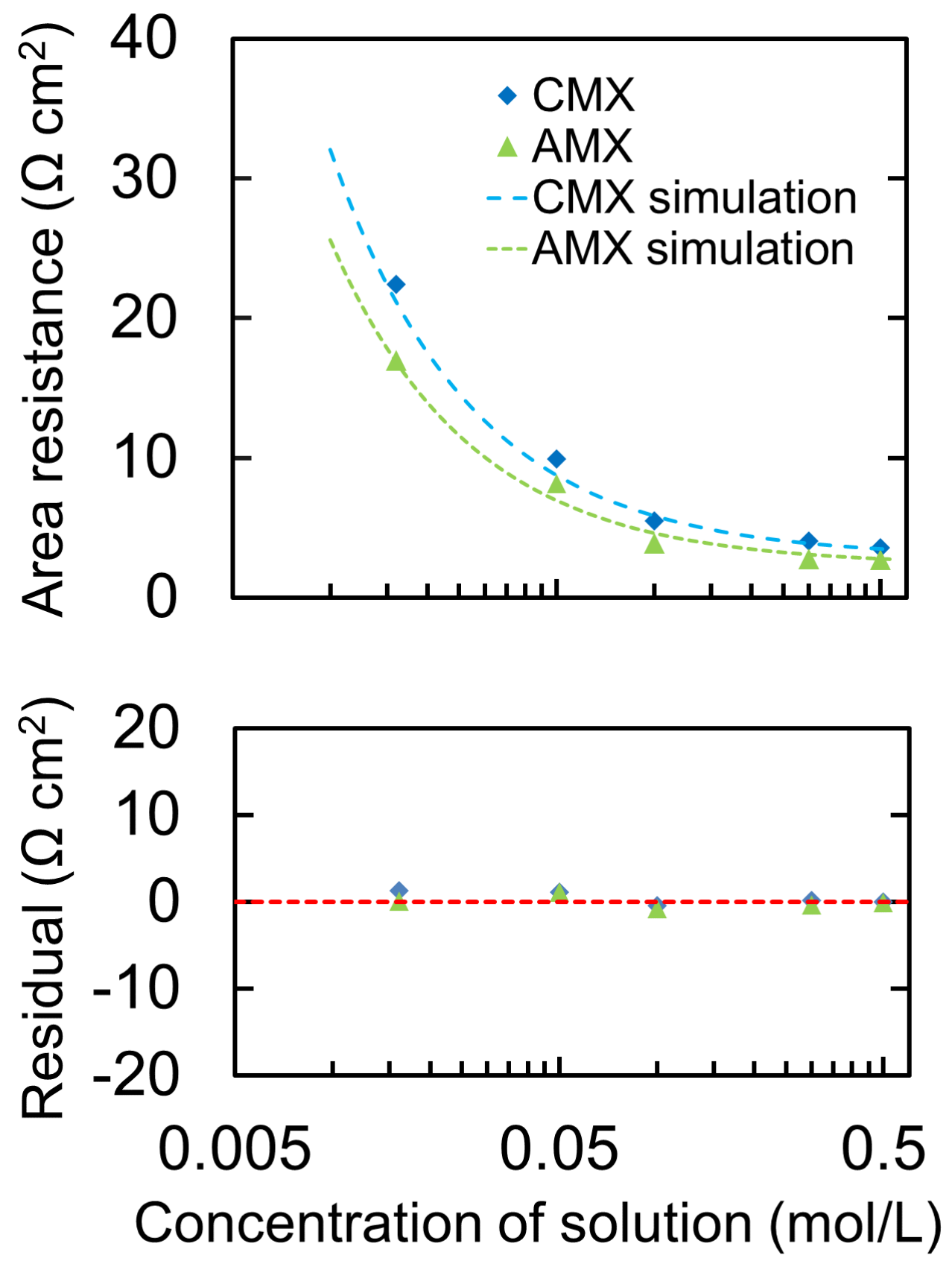

411 Figure 6. Simulation of the concentration dependency of CMX and AMX membrane 412 resistance compared to the data reported in Dlugolecki et al. (2008). Residues of the data 413 to the model simulation values are also presented. 
416 Membrane resistance measured using different current densities in $0.1 \mathrm{~mol} / \mathrm{L} \mathrm{NaCl}$

417 solution are compared with the model prediction of resistance at different current

418 densities in Figure 7. Using the same $\delta$, the current density ratio $r$ was calculated based

419 on different limiting current densities for FKS and FAS membranes as measured in this

420 study (Table 1). The model shows a relatively good prediction at $r$ values studied with $\mathrm{R}^{2}$

421 of 0.930 for FKS and 0.844 for FAS. Variation of resistance with respect to the $r$ value

422 showed an apparent increasing trend when higher $r$ values were applied. As depicted in

423 Eq. 22, current density applied to the system directly affects the concentration

424 distribution within the DBL which alters the resistance of the DBL and results in a non-

425 ohmic resistance.

426 Concentration polarization has been well studied, but the effect of applied current density

427 on the membrane resistance measurement is rarely researched in literature $[11,14,19$,

428 22]. A common practice of resistance measurement applies DC at different current

429 densities to a membrane equilibrated in a solution of certain concentrations $[12,14,25]$.

430 Under this condition, even though the DBL thickness can be controlled

431 hydrodynamically, the resistance resulting from the DBL would vary because different

432 current densities are applied. The extent of concentration polarization under various

433 current densities causes inaccuracies in the results in applications of electrodialysis and

434 RED. Barragan and Ruiz-Bauza (1998) reported a model simulating the change in

435 resistance due to the concentration polarization near the solution-membrane interface for

436 electrodialysis application. However, not all non-ohmic resistance was considered in their

437 model, and the membrane bulk resistance was not associated with membrane properties.

438 In an electrodialysis system, high current ratio situations are common. As indicated in 
439 this study, membrane resistance behavior is considerably different from measurements

440 [3]. 

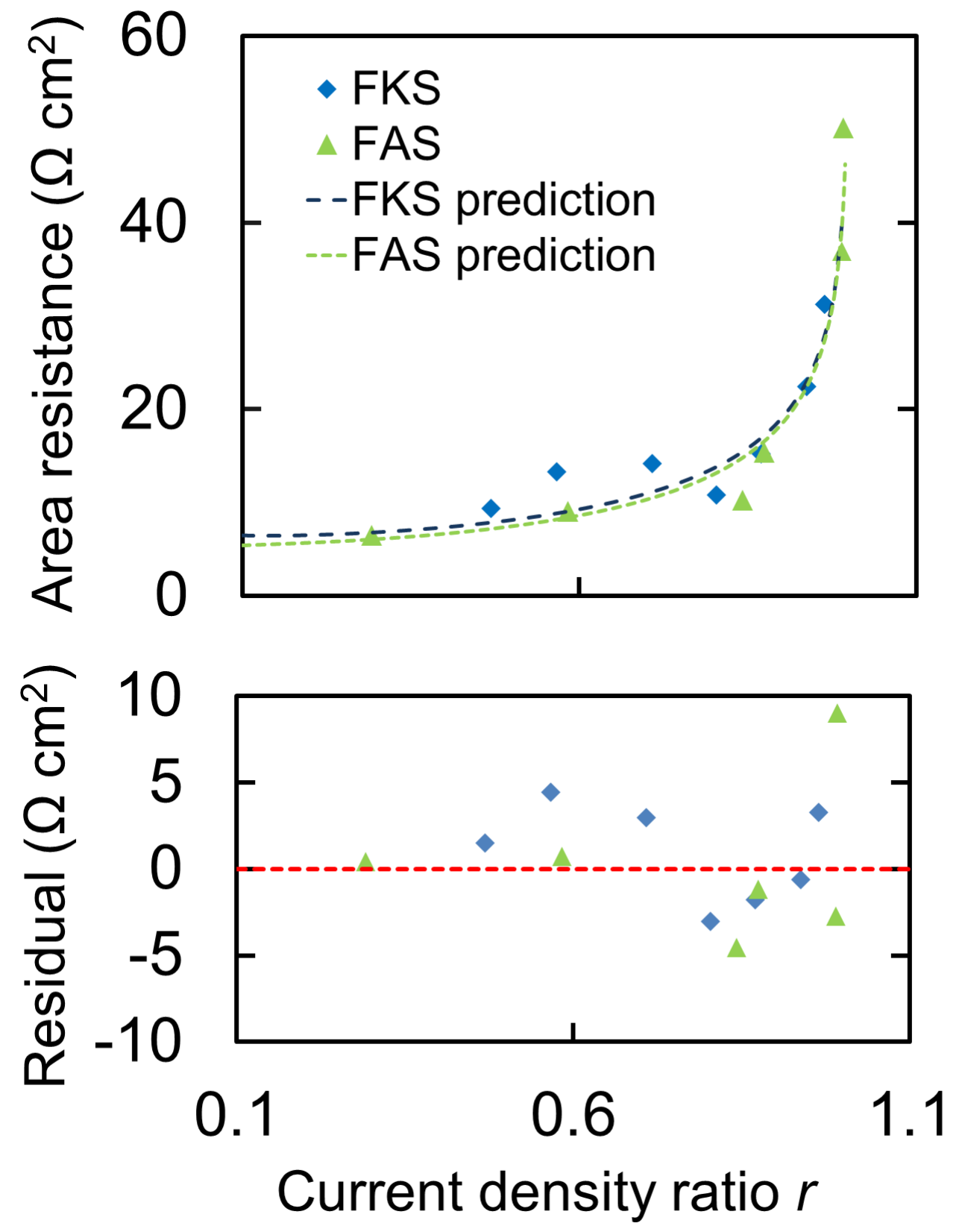

443 Figure 7. The effect of applied current density on the measured membrane resistance.

444 Predictive curve and experimental data are compared and residues are presented.

\section{$446 \quad 4.4$ Implication to Membrane Synthesis and IEM Applications}

447 Because of the dependency of resistance to membrane thickness, a high performance ion-

448 exchange membrane should have the least thickness possible in a specific application, as 
449 long as the mechanical strength permits. Given a fixed membrane thickness, 450 electrochemical properties characterized by $M$ determines the resistance. However, as 451 simulated in Figure 8, improvement of membrane properties can be easily diminished 452 when the system is applied under low electrolyte concentration or at high current density 453 ratio. The resistance from the DBLs, as a combination of resistance due to change of 454 electrolyte concentration and resistance generated from diffusion potential and membrane 455 potential, is more pronounced when the external solution concentration is lower, whereas 456 the resistance of the membrane bulk stays the same over the full concentration range 457 examined. Similarly, experimental data from RED stack design studies indicate that the 458 diluted solution compartment contributes the most to the internal resistance $[19,45]$.

459 Therefore, improvement of performance for a system such as RED (usually concentration 460 level of fresh water encountered) requires not only superb membrane properties, but also 461 practical approaches to decreasing concentration polarization. In an electrodialysis 462 system for desalination, the situation is even worse because the applied current density 463 could easily be close to the limiting current density. 


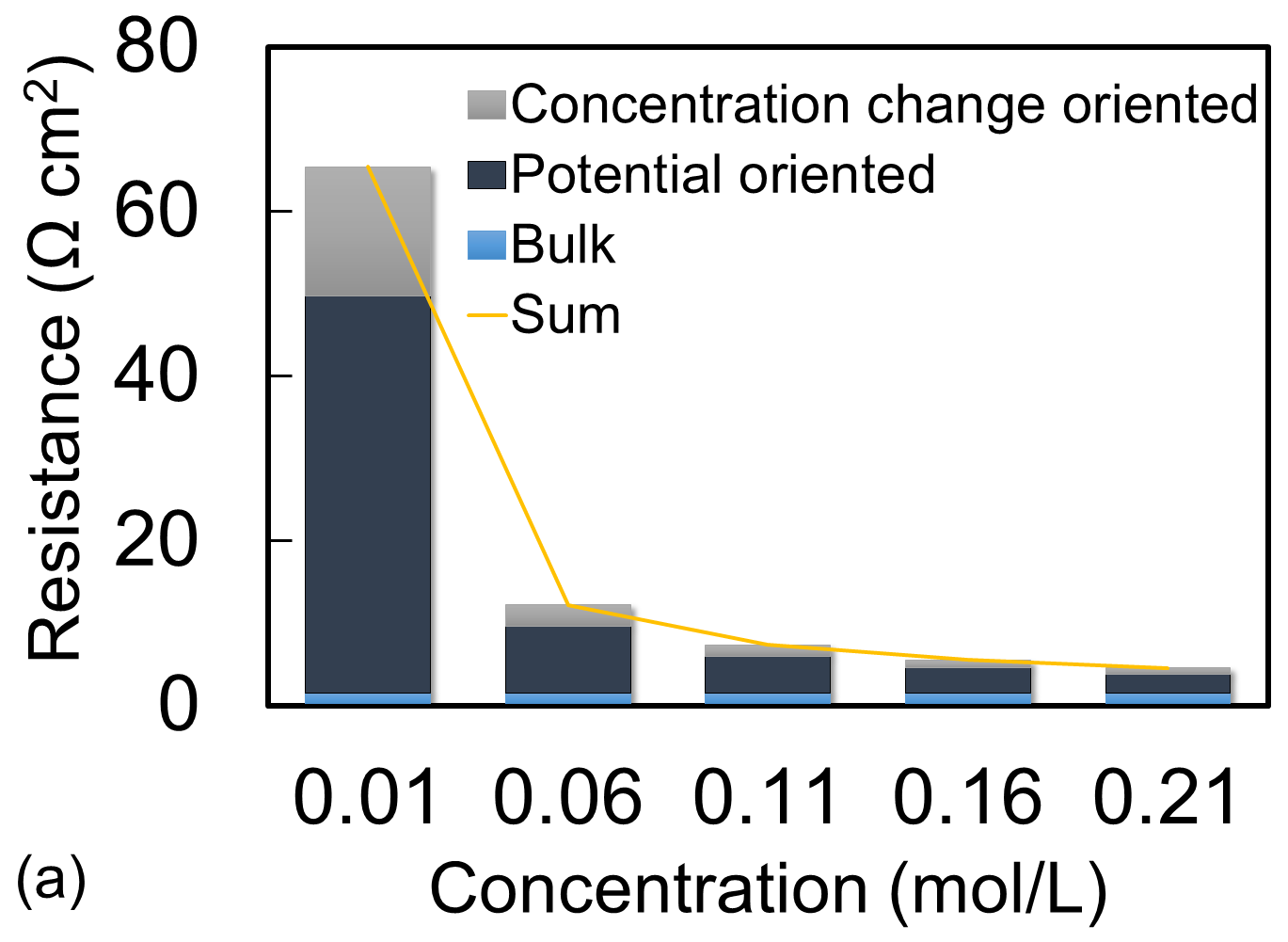

464

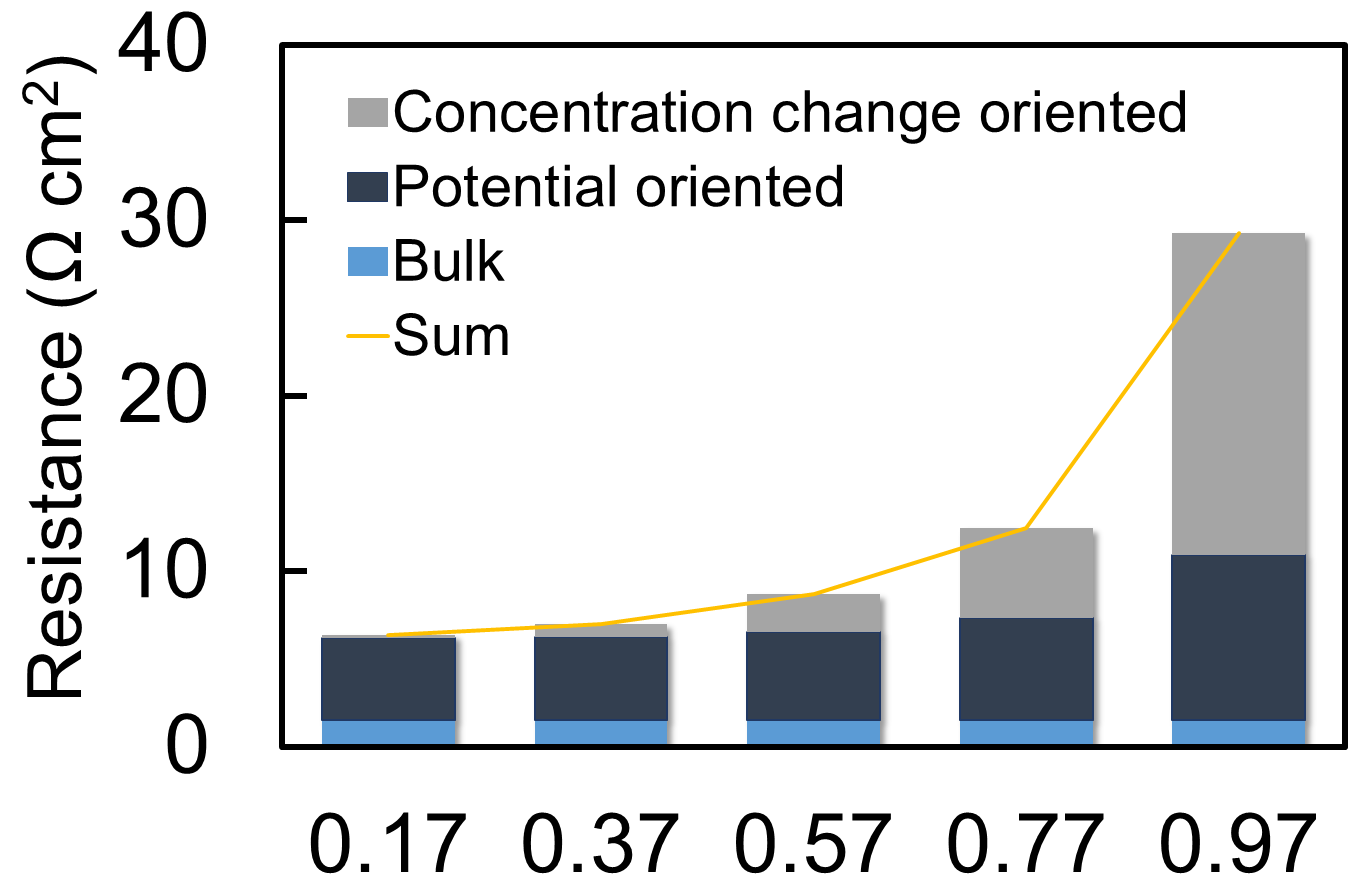

(b)

\section{Current ratio $r$}

466 Figure 8. Simulation of contributions to the apparent resistance of a FKS membrane.

467 DBL thickness is set to $1.0 \mathrm{~mm}$. "Bulk" denotes the resistance from membrane material

468 (first term in Eq. 22c); "Concentration change oriented" denotes the resistance calculated

469 from Eq. 22b; and "Potential oriented" denotes the resistance calculated from the second 
470 term in Eq. 22c. (a) With the same $r=0.5$, the simulated membrane resistance in $\mathrm{NaCl}$ 471 solution of a concentration varies from $0.01 \mathrm{~mol} / \mathrm{L}$ to $0.21 \mathrm{~mol} / \mathrm{L}$. (b) With the same $\mathrm{NaCl}$ 472 solution concentration of $0.1 \mathrm{~mol} / \mathrm{L}$, the simulated membrane resistance when applied has 473 a current density ratio that can vary from 0.17 to 0.97 . 


\section{5. Conclusions}

475 A model of internal ionic resistance in a RED system has been developed by considering

476 the DBL and IEM bulk properties. The model explains the widely reported phenomena 477 theoretically and verifies them with experimental and reported data. Prediction of

478 membrane resistance matched well with experimental data on commercial FKS and FAS

479 membranes, as well as in-house fabricated SPPO membranes.

480 The increase in membrane resistance in a solution with decreased concentration is well 481 explained by the contribution of the DBL to the overall membrane resistance. The model 482 also reveals a linear relationship between the measured membrane resistance and the 483 reciprocal of the external solution concentration when using the DC method. Moreover, 484 the model considers the influence of applied current density, which may affect the 485 resistance of an IEM, especially when the salt concentration is relatively low $(<0.1$ $486 \mathrm{~mol} / \mathrm{L}$ ) and the applied current density is higher than $90 \%$ of the limiting current density $487 \quad(r>0.9)$.

488 To the best of our knowledge, few studies have focused on quantifying the contributions 489 of the DBL and membranes in terms of their ionic resistance with respect to the current 490 density. Using the model presented here, a practical estimation of the resistance of 491 systems such as electrodialysis and RED would be more accurate.

\section{Acknowledgements}

494 This research was partially supported by the U.S. National Science Foundation (NSF

495 Grant no. CBET-1235166) and the Litree Purification Company. 
497 [1] J.W. Post, J. Veerman, H.V.M. Hamelers, G.J.W. Euverink, S.J. Metz, K. Nymeijer, C.J.N. 498 Buisman, Salinity-gradient power: Evaluation of pressure-retarded osmosis and reverse 499 electrodialysis, J Membrane Sci, 288 (2007) 218-230.

500 [2] E. Güler, R. Elizen, D.A. Vermaas, M. Saakes, K. Nijmeijer, Performance-determining 501 membrane properties in reverse electrodialysis, J Membrane Sci, 446 (2013) 266-276.

502 [3] H. Strathmann, Electrodialysis, a mature technology with a multitude of new applications, 503 Desalination, 264 (2010) 268-288.

504 [4] J.P. Denoncourt, Y. Oren, L.M. Woo, Y. Egozy, High-Purity Water by Electrodeionization-Ii - Operation on Hard Water, Abstr Pap Am Chem S, 197 (1989) 152-IAEC.

[5] X. Zhu, M.C. Hatzell, R.D. Cusick, B.E. Logan, Microbial reverse-electrodialysis chemicalproduction cell for acid and alkali production, Electrochemistry Communications, 31 (2013) 5255 .

[6] H.K. Hansen, L.M. Ottosen, A. Villumsen, Electrical resistance and transport numbers of ionexchange membranes used in electrodialytic soil remediation, Sep Sci Technol, 34 (1999) 22232233.

[7] E. Guler, R. Elizen, M. Saakes, K. Nijmeijer, Micro-structured membranes for electricity generation by reverse electrodialysis, J Membrane Sci, 458 (2014) 136-148.

[8] J.G. Hong, Y. Chen, Nanocomposite reverse electrodialysis (RED) ion-exchange membranes for salinity gradient power generation, J Membrane Sci, 460 (2014) 139-147.

[9] E. Guler, Y.L. Zhang, M. Saakes, K. Nijmeijer, Tailor-Made Anion-Exchange Membranes for Salinity Gradient Power Generation Using Reverse Electrodialysis, Chemsuschem, 5 (2012) 2262-2270.

[10] J.W. Post, H.V.M. Hamelers, C.J.N. Buisman, Energy recovery from controlled mixing salt and fresh water with a reverse electrodialysis system, Environ Sci Technol, 42 (2008) 5785-5790.

[11] S. Nouri, L. Dammak, G. Bulvestre, B. Auclair, Comparison of three methods for the determination of the electrical conductivity of ion-exchange polymers, Eur Polym J, 38 (2002) 1907-1913.

[12] P. Dlugolecki, P. Ogonowski, S.J. Metz, M. Saakes, K. Nijmeijer, M. Wessling, On the resistances of membrane, diffusion boundary layer and double layer in ion exchange membrane transport, J Membrane Sci, 349 (2010) 369-379.

[13] P. Dlugolecki, K. Nymeijer, S. Metz, M. Wessling, Current status of ion exchange membranes for power generation from salinity gradients, J Membrane Sci, 319 (2008) 214-222.

[14] P. Dlugolecki, B. Anet, S.J. Metz, K. Nijmeijer, M. Wessling, Transport limitations in ion exchange membranes at low salt concentrations, J Membrane Sci, 346 (2010) 163-171.

[15] J.S. Park, J.H. Choi, J.J. Woo, S.H. Moon, An electrical impedance spectroscopic (EIS) study on transport characteristics of ion-exchange membrane systems, J Colloid Interf Sci, 300 (2006) 655-662.

[16] G.M. Geise, M.A. Hickner, B.E. Logan, Ammonium Bicarbonate Transport in Anion Exchange Membranes for Salinity Gradient Energy, Acs Macro Lett, 2 (2013) 814-817.

[17] N.P. Berezina, N.A. Kononenko, O.A. Dyomina, N.P. Gnusin, Characterization of ionexchange membrane materials: Properties vs structure, Adv Colloid Interfac, 139 (2008) 3-28.

[18] V.I. Zabolotsky, V.V. Nikonenko, Effect of Structural Membrane Inhomogeneity on Transport-Properties, J Membrane Sci, 79 (1993) 181-198.

[19] G.M. Geise, A.J. Curtis, M.C. Hatzell, M.A. Hickner, B.E. Logan, Salt Concentration Differences Alter Membrane Resistance in Reverse Electrodialysis Stacks, Environmental Science \& Technology Letters, 1 (2013) 36-39.

544 membrane systems, Electrochim Acta, 62 (2012) 296-304. 
[21] A.H. Galama, D.A. Vermaas, J. Veerman, M. Saakes, H.H.M. Rijnaarts, J.W. Post, 
595 [43] A.A. Moya, A numerical comparison of optimal load and internal resistances in ion596 exchange membrane systems under reverse electrodialysis conditions, Desalination, 392 (2016) $597 \quad 25-33$.

598 [44] K.S. Kim, W. Ryoo, M.-S. Chun, G.-Y. Chung, Simulation of enhanced power generation by 599 reverse electrodialysis stack module in serial configuration, Desalination, 318 (2013) 79-87.

600 [45] D.A. Vermaas, M. Saakes, K. Nijmeijer, Doubled Power Density from Salinity Gradients at 601 Reduced Intermembrane Distance, Environ Sci Technol, 45 (2011) 7089-7095.

602

603 